$$
\begin{gathered}
\text { SANOT8-0367C } \\
\text { SAND- } 98-0367 C
\end{gathered}
$$

\title{
Size dependence of selectively oxidized VCSEL
} transverse mode structure

$$
\text { CONF-980529-- }
$$

S.P. Hegarty, G. Huyet and J.G. McInerney*

Physics Department, National University of Ireland, University College, Cork, Ireland.

* Also with The Optical Sciences Center, University of Arizona Tucson AZ 85721, U.S.A.

RECEINED FFR 171998

OSTI

E-mail: hegarty@peterhead.ucc.ie

K. D. Choquette, H. Q. Hou, K. M. Geib

Center for Compound Semiconductor Science and Technology, Sandia National Laboratories Albuquerque, NM 87185-0603

\begin{abstract}
We analyze the transverse modes of small index confined VCSELs as a function of aperture size and show that thermal lensing will influence strongly the spectrum of small $(<3 \mu \mathrm{m})$ lasers.
\end{abstract}

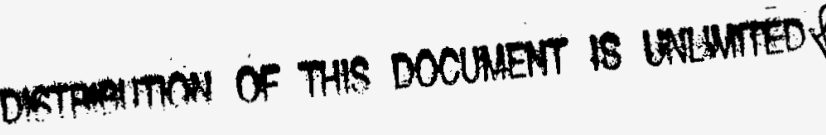

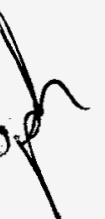




\section{DISCLAIMER}

This report was prepared as an account of work sponsored by an agency of the United States Government. Neither the United States Government nor any agency thereof, nor any of their employees, makes any warranty, express or implied, or assumes any legal liability or responsibility for the accuracy, completeness, or usefulness of any information, apparatus, product, or process disclosed, or represents that its use would not infringe privately owned rights. Reference herein to any specific commercial product, process, or service by trade name, trademark, manufacturer, or otherwise does not necessarily constitute or imply its endorsement, recommendation, or favoring by the United States Government or any agency thereof. The views and opinions of authors expressed herein do not necessarily state or reflect those of the United States Government or any agency thereof. 


\title{
Size dependence of selectively oxidized VCSEL transverse mode structure
}

\author{
S.P. Hegarty, G. Huyet and J.G. McInerney* \\ Physics Department, National University of Ireland, \\ University College, Cork, Ireland. \\ * Also with The Optical Sciences Center, University of Arizona \\ Tucson AZ 85721, U.S.A. \\ E-mail: hegarty@peterhead.ucc.ie

\section{K. D. Choquette, H. Q. Hou, K. M. Geib} \\ Center for Compound Semiconductor Science and Technology, \\ Sandia National Laboratories Albuquerque, NM 87185-0603
}

The performance of vertical cavity surface emitting lasers (VCSELs) has improved greatly in recent years [1],[2],[3]. Much of this improvement can be attributed to the use of native oxide layers within the laser structure, providing both electrical and optical transverse confinement. Understanding this optical confinement will be vital for the future realisation of yet smaller lasers with ultralow threshold currents. Here we report the spectral and modal properties of small $(0.5 \mu \mathrm{m}$ to $5 \mu \mathrm{m}$ current aperture) VCSELs and identify Joule heating as a dominant effect in the resonator properties of the smallest lasers.

The lasers studied here were AlGaAs structures with semiconductor DBRs where the selectively oxidized confinement layer is pulled back 3 mirror periods from each side of the active region to produce a lateral effective index difference of 0.05 [3]. A series of lasers with different aperture sizes were fabricated by etching square mesas through the active region and oxidising laterally the high Al content layer [4]. The difference in side length between succesive mesas was $0.5 \mu \mathrm{m}$. The lasers were operated on a temperature controlled probe station and the laser emission was coupled to a monochromator with $24 \mathrm{GHz}$ resolution.

In Fig. 1 we plot, for a $1 \mu \mathrm{m}$ laser, the separation between the 0 th and 1 st order transverse modes versus the injection current. The large modal splitting is indicative of the strong index guiding in these VCSELs. The increase of the separtion with injection current is attributed to the contribution of a parasitic index profile (thermal lens) induced by Joule heating which increases the transverse optical confinement and thus the mode separation. Similar measurements were carried out on lasers with varying aperture sizes 
as shown in Fig. 2. Fig. 2 demonstrates that the rate of change of the modal separation is greatest for the smallest VCSELs and that the effect vanishes for devices larger than $\sim 3 \mu \mathrm{m}$ implying that thermal lensing effects have little impact on broad area VCSELs.

To further investigate the resonator characteristics, measurements were made of the size of the fundamental mode as a function of the oxide aperture size as shown in Fig. 3. The data were taken at $1.1 \mathrm{i}_{t} h$, the lasers being imaged onto a CCD array by an $\times 50$ IR microscope objective. For the larger devices the mode is smaller than the aperture and decreases as the aperture decreases. For apertures $\sim 3 \mu \mathrm{m}$ the rate of mode size decrease slows and thus the mode fills the aperture more fully. Eventually for devices $<1.5 \mu \mathrm{m}$ the mode becomes larger than the aperture and increases as the aperture decreases[5]. The behavior of the optical mode for small $(<3 \mu \mathrm{m})$ apertures is consistent with the influence of a parasitic thermal index profile potentially present in the smallest cavity VCSELs. Note this effect will effectively limit the effective cavity diameter, and should be taken into consideration for ultralow threshold VCSELs. Further characterization of effects due to thermal lensing in small area selectively oxidized VCSELs will be reported.

\section{References}

[1] K.L. Lear, K.D. Choquette, R.P. Schneider, Jr., S.P. Kilcoyne, and K.M. Geib, Electron. Lett. 31, 208 (1995).

[2] D. L. Huffaker, D. G. Deppe, K. Kumar, and T. J. Rogers, Appl. Phys. Lett. 6597 (1994).

Sandia is a multiprogram laboratory operated by Sandia Corporation, a Lockheed Martin Company, for the United States Department of Energy under Contract DE-AC04-94AL85000. 


\section{Figure Captions}

Figure 1 - Separation of 0 th and 1 st order transverse modes for $1 \mu \mathrm{m}$ VCSEL plotted against injection current. Heat sink temperature $23 \mathrm{C}$.

Figure 2 - Rate of change of mode separation with injection current plotted versus VCSEL oxide aperture size.

Figure 3 - Width of $3 \mathrm{~dB}$ points of fundamental Gaussian mode at 1.1 times threshold current plotted against VCSEL oxide aperture size. 


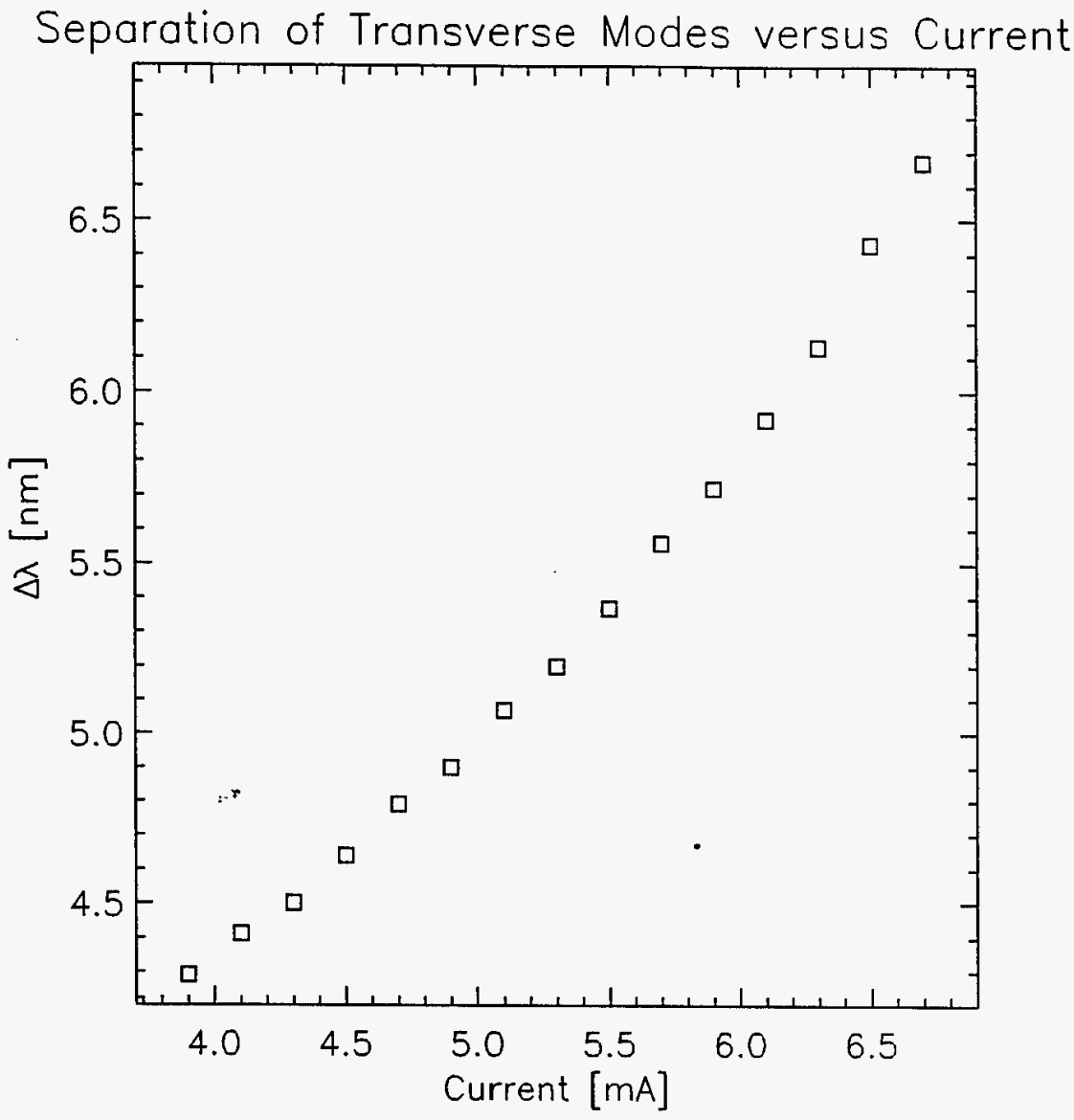

Figure 1 
S. P. Hegarty et al - Size Dependence of VCSEL Transverse Mode... 6

Rate of change of mode separation versus aperture size

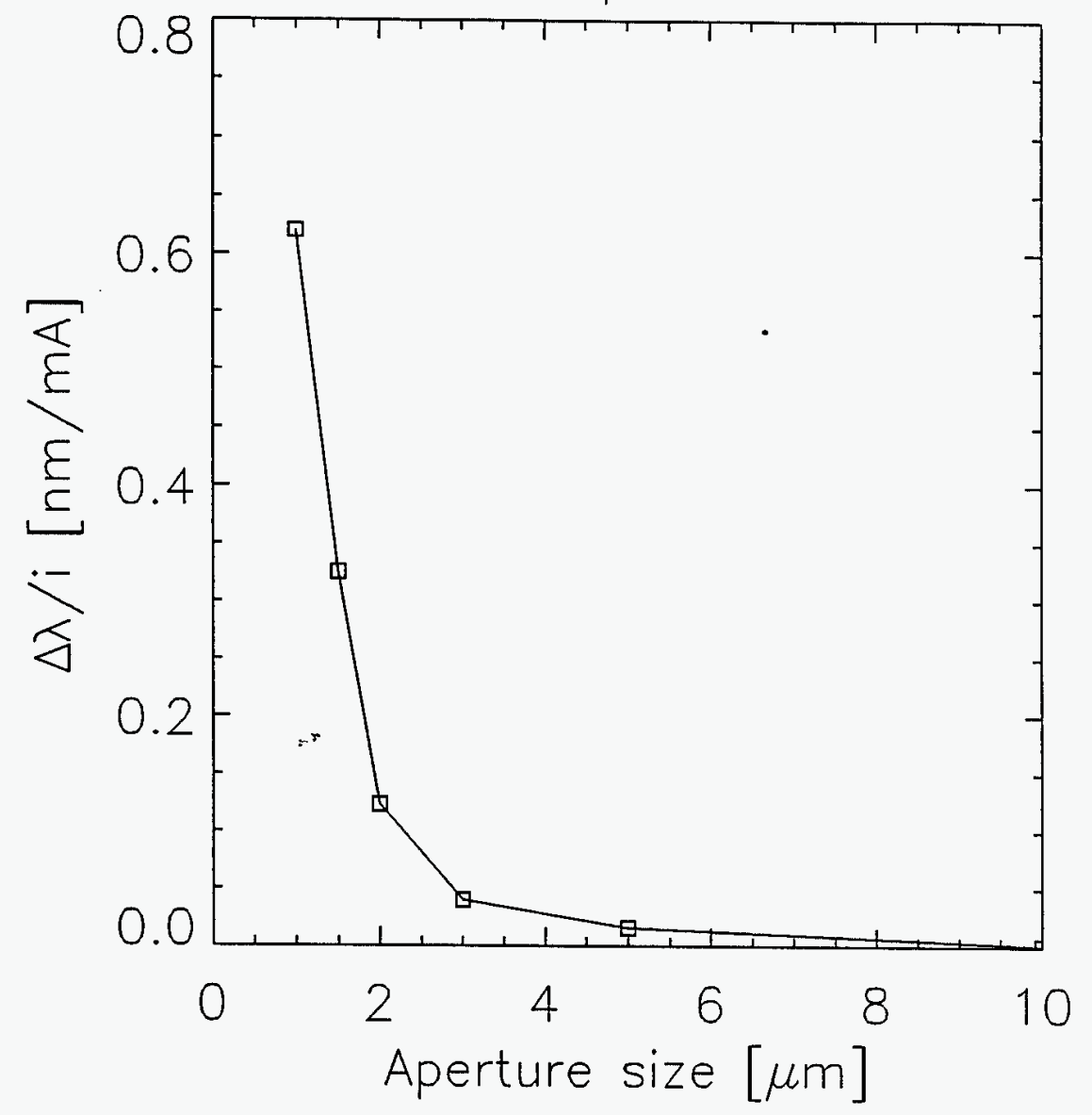

Figure 2 


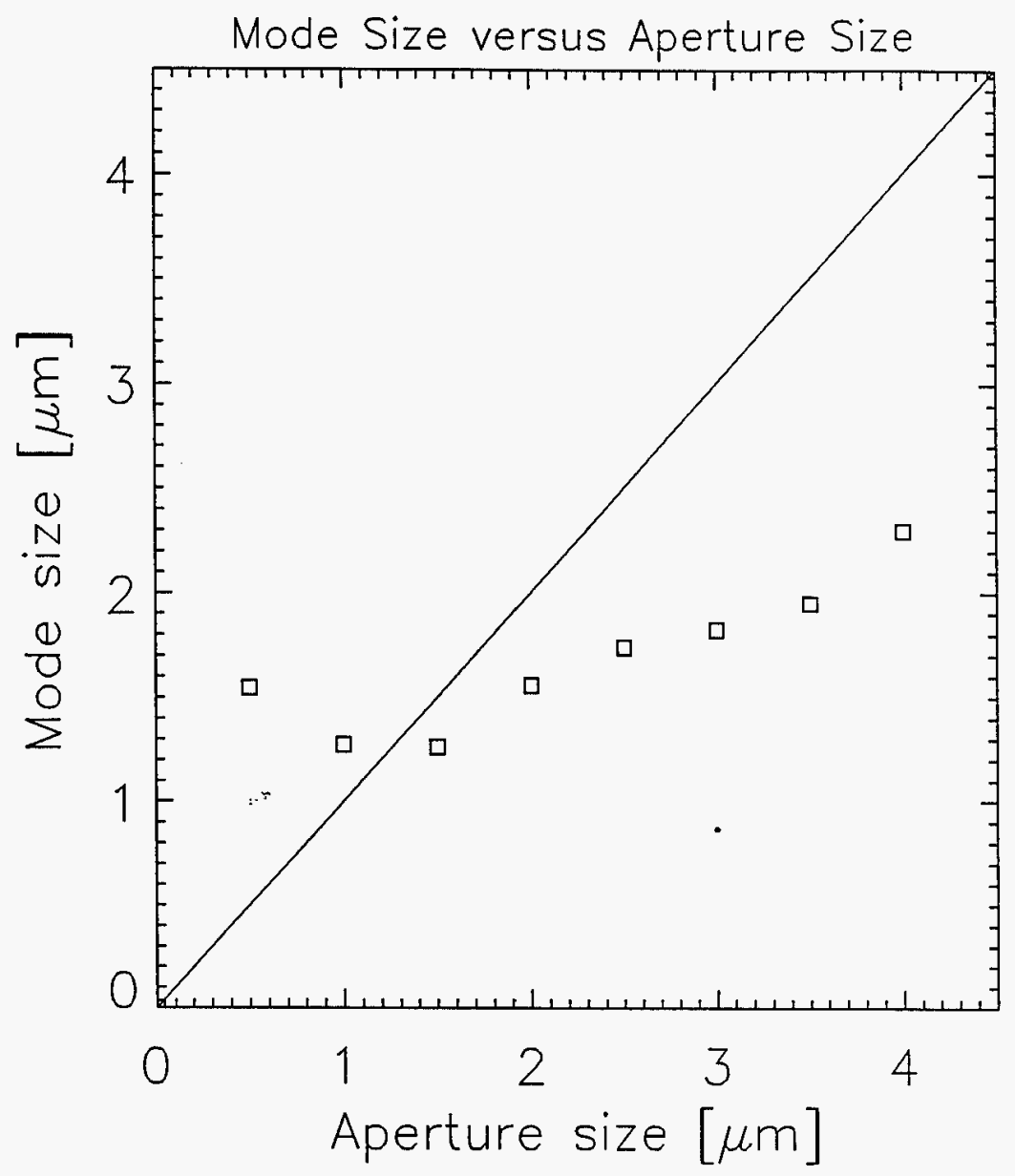

Figure 3 
M98002898

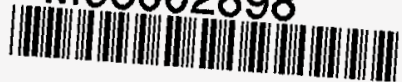

$\frac{\text { Report Number (14) SAND-98-0367C }}{\text { CONF-980529- }}$

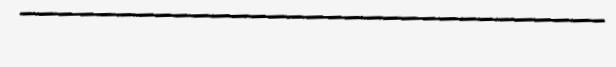

Publ. Date (11)

Sponsor Code (18)

199805

UC Category (19)

DOR/CR,XE

UC-900, DOE/ER 